\title{
Bimbingan Karir Terintegrasi dalam Mata Pelajaran Fisika/Sains
}

\author{
Heriyanto Budiyuwono ${ }^{1}$, Soenarto ${ }^{2}$, Slamet $\mathbf{P H}^{3}$ \\ Program Studi S3 PTK, Pascasarjana Universitas Negeri Yogyakarta, \\ Kampus Karangmalang, Yogyakarta 55281 \\ Email : budiyuwonoagustinus31@gmail.com
}

\begin{abstract}
This study aimed to: (1) help students determine the choice of majors/areas of expertise, (2) improve career guidance services in schools, and (3) produce a pattern of effective career guidance to help students determine school.This study was research by project using Kurt Lewin model. The guidance was held by considering the students' academic and non-academic abilities and the supports of the families, schools and the occupations in order that the students were able to choose schools that fitted their conditions and job opportunities. The study was conducted at SMP Negeri 4 Ponjong. The techniques of collecting the data included: questionnaires, interviews, observation, and documentation. The data were analyzed using Spradley's qualitative data analysis.The conclusions of this study are that: (1) career guidance in SMP requires the involvement of all stakeholders in order to be effective, (2) the existing cooperation is based on the principle of mutual benefit, and (3) the students are able to determine what kind of school they want to enter by considering the employment opportunities and economic conditions.
\end{abstract}

Keywords: Action research, career guidance, SMP

Abstrak: Studi ini bertujuan untuk: (1) membantu siswa menentukan pilihan jurusan/ bidang keahlian, (2) meningkatkan pelayanan bimbingan karir di sekolah, dan (3) menghasilkan pola bimbingan karir yang efektif untuk membantu siswa menentukan sekolah lanjutan. Studi ini merupakan penelitian tindakan yang mempergunakan model penelitian Kurt Lewin. Bimbingan dilakukan dengan mempertimbangkan kemampuan akademis dan nonakademis siswa, daya dukung keluarga, sekolah dan dunia kerja guna mengarahkan siswa pada pilihan sekolah yang sesuai dengan kondisi siswa, dan peluang dunia kerja. Studi dilakukan di SMP Negeri 4 Ponjong. Teknik pengumpulan data yang dipergunakan dalam studi ini meliputi: kuesioner, wawancara, observasi, dan dokumentasi. Data dianalisis secara kualitatif menggunakan model Spradley. Kesimpulan dari studi ini adalah (1) bimbingan karir di SMP memerlukan keterlibatan semua stakeholder agar dapat berjalan dengan efektif, (2) kerjasama yang terjalin berdasarkan prinsip saling menguntungkan, dan (3) siswa mampu membuat pilihan sekolah lanjutan dengan mempertimbangkan peluang kerja dan kondisi ekonomi.

Kata Kunci: penelitian tindakan, bimbingan karir, SMP

\section{Pendahuluan}

Ide penelitian ini berawal dari kesulitan yang dialami oleh sebagian besar siswa kelas 9 semester 1 di SMP Negeri 4 Ponjong berkaitan dengan penentukan pilihan sekolah lanjutan. Kesulitan pertama muncul ketika siswa harus mengidentifikasi dan memilih sekolah lanjutan yang sesuai dengan kemampuan diri. Kesulitan kedua menyertai kesulitan pertama yaitu ketika siswa dihadapkan pada pilihan jurusan dan kompetensi keahlian di sekolah lanjutan tersebut. Kesulitan ketiga yang sering diabaikan oleh siswa adalah memperhitungkan adanya peluang kerja.

Sesuai dengan apa yang menjadi pemikiran Winkel \& Srihastuti (2009:211) dan Belkin (2010:185), bahwa ketepatan dalam memilih sekolah lanjutan dan jurusan diperlukan oleh siswa untuk meraih kesempatan yang lebih baik dalam memperoleh pendidikan dan pekerjaan. Dengan kata lain, pilihan sekolah lanjutan memberikan kesempatan yang berbeda 
dalam mendapatkan pekerjaan. Oleh karena itu bimbingan karir diperlukan guna membantu siswa membuat beberapa keputusan yang tepat berkaitan dengan pilihan sekolah lanjutan untuk meraih karir yang direncanakan.

Kesenjangan antara kebutuhan siswa untuk mengambil keputusan dan apa yang bisa disediakan sekolah, menjadi alasan utama mengapa penelitian ini perlu dilakukan. Setidaknya dua hal yang ingin dicapai dalam penelitian ini. Pertama, membantu siswa menentukan sekolah lanjutan yang tepat. Kedua, untuk membantu membangun pola bimbingan karir yang dapat berfungsi dengan baik di sekolah.

Sebagaimana disampaikan oleh Havighurst (1965:2) bahwa salah satu tugas perkembangan yang harus diselesaikan oleh siswa adalah memilih dan mempersiapkan diri untuk suatu jenis pekerjaan. Persiapan yang dilakukan oleh siswa SMP sesuai tingkat perkembangannya adalah menentukan sekolah lanjutan yang mengarah pada pekerjaan tertentu. Penyelesaiaan tugas pada tahap ini akan mempengaruhi penyelesaian tugas tahap berikutnya, jika siswa tidak mampu menyelesaikannya dengan baik maka timbul kesulitan untuk menyelesaikan tugastugas perkembangan berikutnya.

Menurut Chudzikowski, et al. (2009:123) dan Dominico, \& Karen, (2007:79), kurangnya informasi mengenai dunia kerja mengakibatkan siswa melakukan pilihan dengan mempergunakan pertimbangan yang tidak layak sebagai acuan. Hal tersebut dapat mengakibatkat siswa memilih sekolah lanjutan yang tidak sesuai dengan keadaan individu siswa dan tuntutan sosial. Pemilihan sekolah lanjutan yang kurang tepat dapat menimbulkan kesulitan bagi siswa dalam proses belajar maupun kesulitan dalam memperoleh dan mempertahankan pekerjaan. Bimbingan berupa penyediaan informasi, dialog, saran dan beberapa kegiatan yang berkaitan dengan persiapan karir menjadi tuntutan mutlak dilakukan ditingkat sekolah sebelum individu memasuki sekolah lanjutan yang telah mengarah pada suatu jenis pekerjaan tertentu.

Penelitian ini dimaksudkan untuk memperbaiki pola bimbingan karir yang telah ada dan dapat dipergunakan untuk membantu siswa memahami kondisi diri dan kondisi lingkungan kerja, sehingga siswa mampu memadukan keduanya untuk menentukan pekerjaan yang cocok baginya dan merencanakan pendidikan lanjutan untuk meraih pekerjaan tersebut. Mempertimbangkan hal tersebut maka penelitian yang dilakukan memiliki tujuan: (1) mendapatkan person/lembaga yang dapat membantu guru BK secara efektif meningkatkan pemahaman diri siswa terhadap kemampuan diri, dunia kerja, peluang usaha dan jenis-jenis karir, (2) menemukan peran yang cocok bagi person/lembaga yang terlibat dalam bimbingan karir siswa, (3) menghasilkan perbaikan terhadap pola bimbingan karir yang telah ada.

Furbish (2013: 14-20) melakukan studi berkaitan dengan best practices pendidikan karir di secondary schools New Zealand. Terdapat 20 sekolah yang memenuhi syarat sebagai sekolah yang menerapkan best practices pendidikan karir. Kategori sekolah ini antara lain: (a) sekolah memiliki program khusus pengenalan karir; (b) keterlibatan praktisi dalam pengenalan karir; (c) sekolah membimbing siswa mengenali kemampuan diri; dan (d) sekolah mendampingi siswa melakukan pilihan-pilihan karir.

Schloss, J. (2011: 4-9) Melakukan studi mengenai pengembangan karir di sekolah. Kemampuan guru menjadi pusat studi yang dilakukan. Studi ini menampilkan bahwa sebagian besar guru kurang memperhatikan perkembangan karir. Banyaknya tugas dan tuntutan yang harus dipenuhi menyita waktu guru untuk memikirkan perkembangan karir. Pembelajaran perlu di desain sehingga guru memiliki waktu untuk memikirkan karir. Keterlibatan beberapa pihak diluar sekolah dapat membantu guru mengatasi kekurangannya. 
Sherry \& Staley (1984: 155-159) melakukan studi berkaitan dengan pilihan karir. Pemberian informasi berbagai kegunaan praktis dari materi belajar dikelas mempengaruhi pemahaman anak mengenai kerja. Materi pembelajaran didesain sedemikian hingga sampai pada taraf aplikasi. Aplikasi yang ada dicocokkan dengan beberapa pekerjaan yang memanfaatkannya dengan gradasi yang berbeda. Mutu pilihan yang dilakukan oleh anak bergantung bagaimana interaksi antara pembelajaran dengan jenis-jenis karir yang ada.

\section{Metode Penelitian}

Penelitian ini dimaksudkan untuk meningkatkan mutu pelayanan bimbingan karir kepada siswa oleh sekolah sebagaimana disebutkan sebelumnya. Peningkatan mutu ini dilakukan dengan mengoptimalkan peran guru BK dan guru matapelajaran dalam mengelola proses belajar mengajar di sekolah. Beberapa hal terkait penelitian ini adalah: penelitian dilakukan untuk menyempurnakan praktik bimbingan karir di sekolah, dimana peneliti bekerja. Seluruh proses penelitian ini diawali oleh rasa kurang puas terhadap praktik bimbingan karir yang masih menyisakan kebimbangan siswa dalam menentukan pilihan sekolah lanjutan. Observasi dan evaluasi terhadap pelaksanaan bimbingan karir menjadi masukan bagi perencanaan bimbingan karir berikutnya. Gagasan-gagasan baru sebagai hasil evaluasi ditindaklanjuti sejauh menghasilkan peningkatan suasana belajar yang menyenangkan dan berguna bagi siswa dan guru. Pelaksanaan pembelajaran dirancang peka terhadap suasana dinamis kelas, sehingga dapat terjadi perubahan pelaksanaan sesuai dinamika kelas. Peneliti adalah guru yang terlibat langsung dalam perubahan yang diinginkan. Oleh karena itu jenis penelitian yang digunakan adalah Action Research model Kurt Lewin.

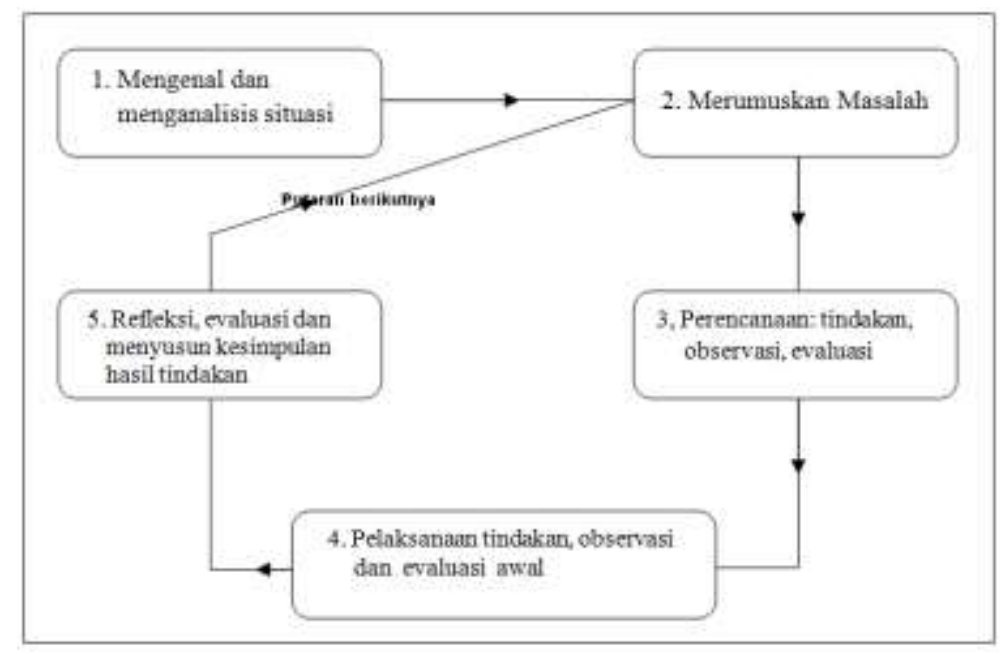

Gambar 1. Alur model Kurt Lewin dalam Penelitian

Model Kurt Lewin memiliki langkah yang sederhana dan mengarah pada penyelesaian masalah penelitian. Dua hal tersebut menjadi alasan utama model Kurt Lewin dipilih dalam penelitian ini guna menyelesaikan masalah bimbingan karir. Siklus-siklus kecil dimungkinkan terjadi pada beberapa langkah, hal ini dilakukan sebagai bentuk adaptasi terhadap situasi dan kondisi lapangan.

Langkah pertama, informasi yang diperoleh dari guru dicari hubungannya dengan informasi yang berasal dari siswa. Dari langkah ini diperoleh gambaran keberterimaan informasi mengenai karir yang telah diupayakan oleh guru. Pendalaman lebih detail mengenai hal tersebut dilanjutkan dalam langkah ke dua penelitian ini. 
Langkah kedua, merupakan pencarian fakta berkaitan bimbingan karir di sekolah. Pencarian fakta ini menindaklanjuti angket yang diisi siswa dan guru. Data dalam angket dicek kebenarannya melalui pengamatan, wawancara dan membandingkannya dengan dokumen yang ada. Fakta yang diperoleh meliputi pelaksanaan bimbingan karir yang sudah berjalan, pemahaman siswa terhadap kemampuan diri, dunia kerja, dan sekolah lanjutan. Kemampuan diri siswa dikelompokkan menjadi dua, yaitu kemampuan akademis dan kemampuan non akademis. Tingkat pemahaman siswa terhadap kemampuan akademis yang dimilikinya dilakukan dengan membandingkan penilaian guru dengan penilaian siswa pada masing-masing mata pelajaran. Penilaian oleh guru bersumber pada dokumen sekolah. Pemahaman siswa terhadap kemampuan non akademis diperoleh melalui wawancara dan pengamatan kegiatan sekolah yang diikuti siswa. Berbagai diskusi mengenainya dengan siswa yang bersangkutan menumbuhkan pemikiran-pemikiran yang memperkaya pengetahuan siswa. Wawancara yang disertai diskusi ini memberikan gambaran yang cukup lengkap mengenai kebutuhan siswa dan apa yang belum diperoleh dari pembelajaran yang telah dijalani. Gambaran yang cukup lengkap ini ditindaklanjuti dengan penyusunan rencana bimbingan karir pada langkah ketiga berikut.

Langkah ketiga, menyusun strategi bimbingan karir. Penyusunan rencana bimbingan karir ini mempertimbangkan dua hal, yaitu hasil wawancara pada langkah kedua dan usulan-usulan dari guru pada masing-masing sekolah yang bersangkutan. Kesepakatan diperlukan mengingat kolaborasi yang dilakukan melibatkan latar belakang pendidikan yang berbeda. Apa yang direncanakan pada tahap ini dijadikan acuan pokok pelaksanaan tindakan penelitian. Rencana tindakan ini merupakan rancangan langkah yang mengarah pada suatu jenis tindakan nyata. Perencanaan dilakukan secara meyeluruh terhadap semua tindakan, termasuk observasi dan evaluasi. Rancangan langkah dibuat dengan memperhitungkan bahwa semua tindakan sosial dalam batasan tertentu tidak dapat diprediksi. Mengingat hal tersebut maka rancangan di desain bersifat fleksibel agar dapat disesuaikan dengan situasi. Hal ini berarti tindakan yang dipilih diusahakan mampu membantu para guru mengembangkan potensi dengan melakukan tindakan yang tepat menghadapi situasi sosial yang belum pasti.

Langkah keempat, guru melaksanakan rencana pemecahan masalah. Pengamatan dan evaluasi dilaksanakan bersamaan dengan pelaksanaan tindakan. Hal ini dapat diartikan bahwa tindakan yang dilakukan bersifat sadar dan terkendali. Tindakan yang dilakukan dipandu oleh rencana yang telah dibuat, meskipun seperti telah diungkapkan sebelumnya bahwa panduan tindakan tidak bersifat mutlak tetapi menyesuaikan kondisi nyata lapangan. Hal ini mendorong perlunya observasi dan evaluasi dilakukan bersamaan dengan tindakan. Hal-hal yang perlu diobservasi dan dievaluasi antara lain: proses tindakan, pengaruh tindakan termasuk respon, pengaruh respon terhadap tindakan, situasi, kendala tindakan, pengaruh kendala terhadap tindakan, dan pengaruh lain yang mungkin menyertai tindakan tersebut. Selain itu evaluasi awal berdasarkan observasi perlu dilakukan mengingat terbatasnya daya ingat serta kemungkinan diperlukannya respon yang cepat dari situasi yang ada. Dokumentasi berupa rekaman manual ataupun digital dipergunakan untuk dibahas lebih dalam pada langkah kelima yaitu refleksi dan evaluasi.

Langkah kelima, guru melakukan refleksi, evaluasi berdasarkan dokumen observasi, dan menyusun kesimpulan. Pada proses ini guru-guru mengingat dan mencermati dokumen observasi. Guru mendiskusikan pengalaman dan memberi makna peristiwa sosial yang telah dialami. Pemaknaan peristiwa ini dijadikan dasar untuk memperbaiki perencanaan tindakan selanjutnya.

Kelima langkah diatas diulang jika pemecahan masalah diperhitungkan kurang berhasil. Proses dasar penelitian ini dapat diringkas dalam model satu suklus berikut ini. 


\section{Hasil dan Pembahasan}

\subsection{Personal/lembaga yang terlibat dalam pembelajaran.}

Penentuan personal/lembaga yang terlibat dalam pembelajaran, didasarkan keterlibatan mereka pada siklus pertama hingga ketiga. Pada awal bab ini disampaikan, guru BK dan guru mata pelajaran belum bisa memberikan jawaban atas pertanyaan siswa secara memuaskan. Guru tidak menguasai semua informasi yang diperlukan oleh siswa. Keterbatasan waktu dan ruang memerlukan kerjasama dengan berbagai pihak yang memiliki informasi.

Pihak-pihak yang terlibat sebagai perantara atau secara langsung membantu memberikan informasi atau gambaran nyata tentang kerja antara lain: guru mata pelajaran, koordinator urusan kurikulum, koordinator urusan kesiswaan, koordinator urusan humas, pembina pramuka, komite sekolah, wiraswasta (pengrajin batu/kayu, produsen tempe/tahu/tape, pedagang), petani, humas SMK, humas SMA, humas Puskesmas, humas Bank, humas Polsek, alumni, pekerja profesional (notaris, dokter, bidan), humas perusahaan, tempat wisata, pengelola pasar dan politisi.

\subsection{Peran yang harus dilakukan oleh personal/lembaga yang terlibat dalam pembelajaran.}

Intensitas keterlibatan masing-masing personal/lembaga pada pembelajaran tidaklah sama. Guru BK sebagai pembimbing karir siswa, bertindak sebagai koordinator terlaksananya pembelajaran ini. Guru mata pelajaran memiliki peran penting bagi terlaksananya pembelajaran yang efektif. Beberapa yang harus dilakukan oleh guru antara lain: mencermati materi pembelajaran yang berkaitan dengan pekerjaan tertentu.

Guru mengacu pada KBJI dan O*NET (The Occupational Information Network). Guru menentukan cara yang tepat dan alternatif cadangan untuk menyampaikan materi pembelajaran yang didalamnya memuat informasi mengenai sekolah lanjutan dan pekarjaan. Guru mengajak siswa mengunjungi tempat kerja yang menerapkan materi yang sedang dipelajari. Pada kesempatan lain guru mengundang tenaga profesional yang merupakan praktisi dari materi pelajaran tertentu. Guna memberikan gambaran nyata mengenai sekolah lanjutan guru mengajak siswa mengunjungi sekolah lanjutan. Kunjungan pada sekolah lanjutan dapat ditindak lanjuti dengan mengundang alumni yang sedang/pernah sekolah di tempat tersebut.

Koordinator urusan kurikulum mengatur kerja sama antar guru mata pelajaran untuk menentukan beberapa materi pembelajaran yang dapat dilaksanakan bersama-sama. Koordinator urusan kesiswaan mengatur kerja sama dengan panitia kegiatan kesiswaan untuk memasukkan unsur pengenalan terhadap sekolah lanjutan dan ragam pekerjaan dalam setiap kegiatan yang memungkinkan. Koordinator urusan humas mengatur kerjasama dengan komite, personal/lembaga yang mungkin dapat dilibatkan dalam penyampaian informasi dunia kerja. Kerjasama yang terjalin dituangkan dalam surat perjanjian yang mengatur hak serta kewajiban kedua belah pihak.

Puskesmas memiliki kepentingan terhadap siswa SMP berkaitan dengan visi dan misi yang mereka miliki. Kepentingan Puskesmas terhadap siswa dimanfaatkan untuk penyampaian beberapa materi pelajaran yang berkaitan dengan kesehatan. Kerja sama dengan Puskesmas juga dilakukan pada kegiatan di luar kelas, seperti UKS dan kepramukaan. Siswa pada beberapa kesempatan dimanfaatkan oleh Puskesmas sebagai pembawa pesan hidup sehat kepada anggota masyarakat yang lain. 
Polsek memiliki kepentingan dengan siswa SMP sesuai dengan visi dan misi mereka. Kerja sama antara Polsek dan sekolah antara lain berkaitan dengan penyampaian informasi mengenai keamanan, ketertiban, hukum dan aturan lalu lintas. Pertemuan secara langsung dengan anggota kepolisian memberikan kesempatan kepada siswa untuk bertanya seputar pekerjaan polisi. Selain penanaman kesadaran hukum dan tertib berlalu lintas, siswa diberikan tugas sebagai duta polisi bagi keluarga masing-masing.

Instansi pemerintah yang memiliki kepentingan besar pada siswa SMP adalah Dinas Pendidikan, Pemuda dan Olahraga. Dinas Pendidikan memprioritaskan pada penyuluhan wajib belajar dan meningkatkan kesadaran orang tua untuk menyekolahkan anaknya. Hal tersebut berkaitan dengan masih banyaknya anak usia sekolah yang tidak melanjutkan.

Pekerja profesional merupakan relawan yang membagi pengalaman hidupnya kepada siswa. Ia memberikan informasi mengenai pekerjaan yang ditekuni dan bagaimana cara meraih pekerjaan tersebut. Pemikiran-pemikiran yang dimiliki berkaitan dengan peluang usaha, keterampilan dan pendidikan yang harus ditempuh. Pertemuan dengan pekerja profesional memberikan kesempatan kepada siswa untuk mendapatkan informasi yang lebih spesifik berkaitan pekerjaan yang ditekuni.

Wiraswasta seperti halnya pekerja profesional merupakan relawan yang membagikan informasi berkaitan dengan pekerjaannya, keterampilan yang diperlukan serta peluangpeluang pengembangan dari pekerjaan. Siswa mendapat informasi bagaimana cara melihat peluang usaha dan cara-cara yang diperlukan untuk memulai suatu usaha. Beberapa siswa mendapatkan bimbingan untuk mulai berwiraswasta sambil sekolah.

Alumni yang terlibat merupakan alumni yang masih menempuh pendidikan, baik pendidikan menengah, lembaga pelatihan ataupun yang kuliah. Informasi mengenai apa saja yang dipelajari, suasana tempat belajar, prospek kerja atau melanjutkan dan biaya yang diperlukan merupakan fokus sharing yang mereka lakukan. Pertemuan secara langsung dengan alumni memberikan kesempatan kepada siswa untuk bertanya tentang banyak hal.

Keberhasilan pengenalan sekolah lanjutan dan jenis-jenis pekerjaan ini bergantung dari kerjasama berbagai pihak sebagaimana dijabarkan sebelumnya. Guru pelajaran mendapatkan keuntungan dari kondisi siswa yang lebih bersemangat dengan variasi proses pembelajaran. Polsek mendapatkan keuntungan dari hubungan yang semakin dekat dengan siswa sebagai remaja anggota masyarakat. Ketertiban dan keamanan menjadi lebih terpantau dan terjaga.

Puskesmas mendapatkan keuntungan karena informasi mengenai kesehatan dapat tersebar luas. Kesehatan masyarakat khususnya siswa menjadi lebih terpantau. Beberapa relawan dari tenaga profesional, wiraswasta dan alumni memiliki tanggapan yang positif karena mereka dapat memperoleh pengalaman yang berbeda dari tempat kerja yaitu berhadapan langsung dengan anak-anak.

Berdasarkan kondisi di atas maka pola kerja sama yang efektif adalah kerjasama berdasarkan kesepahaman tercapainya kebutuhan masing-masing instansi atau personal yang terlibat. Kesepahaman ini dituangkan dalam nota kesepahaman yang ditandatangi kedua pihak.

\subsection{Pola bimbingan karir yang efektif untuk membantu siswa meningkatkan kesiapan memilih sekolah lanjutan yang sejalan dengan pergeseran kualifikasi dan peluang kerja.}

Bimbingan agar siswa memiliki kesiapan memilih sekolah lanjutan yang sejalan dengan pergeseran kualifikasi dan peluang kerja tidak dapat hanya mengandalkan guru BK. Tampak dalam penelitian pada siklus pertama hingga ke tiga, bahwa bimbingan yang efektif memerlukan keterlibatan semua pihak, rencana yang matang, pelaksanaan yang terkendali, 
berkesinambungan dan evaluasi. Evaluasi diperlukan agar proses bimbingan selalu dapat disempurnakan.

Bimbingan karir terlaksana secara efektif dengan melibatkan guru BK, koordinator kurikulum, koordinator kesiswaan, koordinator humas, guru mata pelajaran, komite sekolah, panitia kegiatan sekolah, dinas kesehatan setempat, kepolisian setempat, SMK, SMA, wiraswasta, pekerja profesional dan dinas pendidikan. Kerja sama terjalin berdasarkan saling memerlukan antara sekolah dengan pihak yang terkait. Kerja sama dengan berbagai pihak ini dituangkan dalam lembar nota kesepahaman.

\section{Kesimpulan}

Berdasarkan analisis data serta pembahasan yang dilakukan pada bab IV, berikut disampaikan simpulan penelitian yang merupakan jawaban atas permasalahan penelitian yang terdapat pada rumusan masalah. Berikut disampaikan jawaban atas permasalahan secara urut.

\subsection{Personal/Lembaga Yang Terlibat Dalam Pembelajaran}

Usaha untuk meningkatkan pemahaman siswa terhadap dunia kerja, peluang usaha dan jenis-jenis karir memerlukan peran dari: guru mata pelajaran, komite sekolah, SMA dan SMK, Puskesmas, Polsek, instansi pemerintah, pekerja profesional, wiraswasta, alumni, guru BK, koordinator urusan kesiswaan, koordinator urusan kurikulum dan koordinator urusan hubungan kemasyarakatan.

\subsection{Peran Personal/Lembaga.}

Guru memiliki peran penting bagi terlaksananya pembelajaran yang efektif. Guru perlu mencermati materi pembelajaran yang berkaitan dengan pekerjaan tertentu. Guru mengacu pada KJI dan DOT (Dictionary of Occupational Titles) yang berbentuk digital dan dikenal dengan istilah O*NET (The Occupational Information Network). Guru menentukan cara yang tepat dan alternatif cadangan untuk menyampaikan materi pembelajaran yang didalamnya memuat informasi mengenai sekolah lanjutan dan pekarjaan yang berkaitan.

Cara yang biasa ditempuh untuk menyampaikan informasi antara lain mengunjungi tempat kerja yang menerapkan materi pembelajaran tersebut, mengundang tenaga profesional yang menerapkan materi pembelajaran dalam pekerjaannya, mengunjungi sekolah lanjutan yang mempelajari lebih dalam materi tersebut, mengundang alumni/sukarelawan yang sedang mempelajari materi pada pendidikan yang lebih tinggi. Berkoordinasi dengan guru pelajaran lainnya untuk menentukan beberapa materi pembelajaran yang dapat dilaksanakan bersamasama. Guru membuat evaluasi peningkatan pemahaman siswa mengenai materi pembelajaran, pekerjaan yang terkait dan sekolah lanjutan yang sesuai.

Komite Sekolah berperan mendukung terlaksananya proses pembelajaran yang efektif di sekolah. Dukungan ini dapat berupa bantuan mendapatkan tenaga profesional, mempermudah hubungan dengan wiraswasta, SMK, SMA, puskesmas, polsek dan instansi pemerintah lainnya. Sekolah lanjutan berperan dalam pemberian informasi berkaitan dengan jurusan dan bidang keahlian yang dimiliki. Penyampaian informasi sekolah lanjutan diefektifkan melalui pembelajaran di kelas. Kerjasama yang terjalin dituangkan dalam surat perjanjian yang mengatur hak serta kewajiban kedua belah pihak.

Puskesmas memiliki kepentingan terhadap siswa SMP berkaitan dengan visi dan misi yang mereka miliki. Kerja sama untuk mewujudkan visi serta kebutuhan SMP mengenai informasi dituangkan dalam surat kerjasama. Kerja sama dengan puskesmas antara lain penyampaian informasi yang berkaitan dengan kesehatan masyarakat dan individu, tugas puskesmas, tugas dokter, tugas perawat, tugas bidan, sekolah yang harus ditempuh untuk mendapatkan pekerjaan, pekerjaan dan instansi lain yang berhubungan dengan tugas puskesmas. 
Polsek memiliki kepentingan dengan siswa SMP sesuai dengan visi dan misi mereka. Polsek dan sekolah melakukan kerja sama dengan aturan yang tertuang dalam surat perjanjian kerja sama. Kerja sama antara polsek dan sekolah antara lain berkaitan dengan penyampaian informasi mengenai keamanan, ketertiban, hukum dan aturan lalu lintas, tugas polisi, keahlian yang harus dimiliki oleh polisi sekolah untuk menjadi polisi.

Instansi pemerintah yang memiliki kepentingan besar pada siswa SMP adalah Dinas Pendidikan, Pemuda dan Olahraga. Penyuluhan mengenai wajib belajar dan meningkatkan kesadaran orang tua untuk menyekolahkan anak menjadi prioritas utama dinas pendidikan. Penyuluhan yang dilakukan betrkaitan masih banyak siswa lulusan SMP yang tidak melanjutkan ke sekolah menengah. Pekerja profesional merupakan relawan untuk berbagi pengalaman dengan siswa. Ia memberikan informasi mengenai pekerjaan yang ditekuni dan bagaimana cara meraih pekerjaan tersebut. Pemikiran-pemikiran yang dimiliki berkaitan dengan peluang usaha, keterampilan dan pendidikan yang harus ditempuh. Sebagaimana pekerja profesional, wiraswasta merupakan relawan yang membagikan informasi berkaitan dengan pekerjaannya, keterampilan yang diperlukan serta peluang-peluang pengembangan dari pekerjaan.

Alumni yang terlibat merupakan alumni yang masih menempuh pendidikan, baik pendidikan menengah, lembaga pelatihan ataupun yang kuliah. Informasi mengenai apa saja yang dipelajari, suasana tempat belajar, prospek kerja atau melanjutkan dan biaya yang diperlukan merupakan fokus sharing yang mereka lakukan. Guru BK berperan sebagai koordinator terlaksananya program penyampaian informasi mengenai sekolah lanjutan dan jenis-jenis pekerjaan. Kepala urusan kurikulum memfasilitasi kerja sama antar guru mata pelajaran dan melakukan penyempurnaan pada kurikulum untuk menjamin terlaksananya program pengenalan sekolah lanjutan dan jenis-jenis pekerjaan.

Kepala urusan kesiswaan memfasilitasi masuknya program pengenalan sekolah lanjutan dan jenis-jenis pekerjaan pada kegiatan kesiswaan di sekolah. Kepala urusan hubungan kemasyarakatan memfasilitasi hubungan sekolah dengan pihak luar, termasuk menjalin kerja sama dengan instansi pemerintah, puskesmas, polsek, wiraswasta dan pekerja profesional.

\subsection{Pola Kerja Sama Yang Efektif.}

Keberhasilan pengenalan sekolah lanjutan dan jenis-jenis pekerjaan ini bergantung dari kerjasama berbagai pihak sebagaimana dijabarkan sebelumnya. Guru pelajaran mendapatkan keuntungan dari kondisi siswa yang lebih bersemangat dengan variasi proses pembelajaran. Polsek mendapatkan keuntungan dari hubungan yang dekat dengan siswa. Ketertiban dan keamanan menjadi lebih terpantau dan terjaga. Puskesmas mendapatkan keuntungan karena informasi mengenai kesehatan dapat tersebar luas. Kesehatan masyarakat khususnya siswa menjadi lebih terpantau. Beberapa relawan dari tenaga profesional, wiraswasta dan alumni memiliki tanggapan yang positif karena mereka dapat memperoleh pengalaman yang berbeda dari tempat kerja yaitu berhadapan langsung dengan anak-anak.

Berdasarkan kondisi di atas maka kerja sama yang efektif adalah kerjasama berdasarkan kesepahaman tercapainya tujuan masing-masing instansi atau pribadi yang terlibat. Kesepahaman ini dituangkan dalam nota kesepahaman yang ditandatangi kedua pihak.

\subsection{Pola Bimbingan Karir Yang Efektif.}

Siswa SMP berada pada tahap eksplorasi karir. Hasil penelitian ini memperlihatkan bahwa sekolah tidak dapat menguasai semua informasi yang diperlukan oleh siswa. Memperkaya 
guru dengan informasi-informasi terkini mengenai karir dan perkembangan ketenagakerjaan memberikan hasil yang kurang memuaskan. Keterbatasan ini menuntut sekolah melakukan kerja sama dengan berbagai sumber informasi. Kerja sama yang terjalin menempatkan sekolah sebagai pusat hubung dan pengendali aliran informasi dari berbagai sumber kepada siswa.

Berikut langkah dalam membantu siswa mendapatkan informasi yang diperlukan. Siswa dan guru berdiskusi tentang sekolah lanjutan dan karir untuk mengetahui informasi apa saja yang masih diperlukan siswa untuk merencanakan karirnya. Tim guru menentukan sumber informasi yang akan diundang dan menentukan mata pelajaran yang terlibat dalam penyampaian informasi tersebut. Pertanyaan-pertanyaan siswa yang belum dapat dijawab oleh guru dikumpulkan untuk ditanyakan kepada narasumber. Guru BK mencari peluang instansi/perusahaan yang memiliki program layanan sejalan dengan yang diperlukan siswa. Dapat digambarkan pola bimbingan karir dalam diagram berikut.

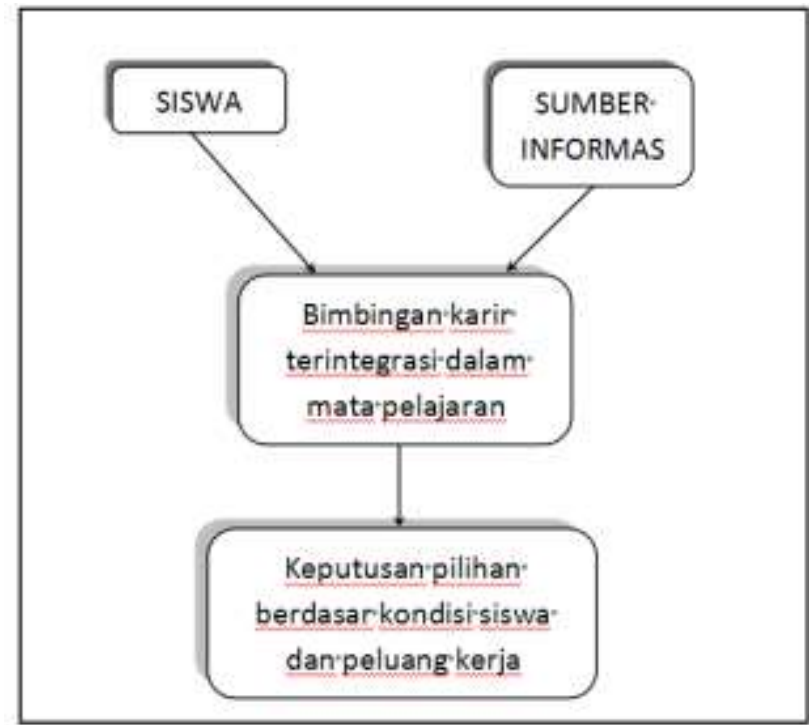

Berdasarkan keterbatasan, keberhasilan penelitian dan kondisi sekolah penulis menyampaikan beberapa saran agar siswa memiliki kemampuan yang memadai untuk menentukan sekolah lanjutan dan rencana karir. Berikut disampaikan saran tersebut: (a) semua guru matapelajaran sebaiknya membantu siswa untuk mengenal sekolah lanjutan dan berbagai pilihan pekerjaan melalui kaitan materi pembelajaran; (b) rencana pengenalan pekerjaan dan sekolah lanjutan sebaiknya dituangkan dalam RPP dan dimasukkan sebagai materi utama; (c) semua kegiatan sekolah sebaiknya memuat unsur pengenalan jenis pekerjaan dan sekolah lanjutan; (d) pengenalan terhadap jenis pekerjaan dan sekolah lanjutan sebaiknya direncanakan dengan matang dengan melibatkan sebanyak mungkin guru matapelajaran; (e) segala bentuk kerja sama dengan instansi pemerintah sebaiknya dituangkan dalam surat perjanjian kesepahaman; (f) sekolah sebaiknya memanfaatkan potensi konselor untuk menghubungkan sekolah dengan dunia kerja; (g) Dinas Pendidikan sebaiknya membekali kepala sekolah dengan keterampilan praktis pengelolaan lingkungan baik lingkungan sosial maupun lingkungan alam. Lingkungan sosial meliputi aspek budaya dan ekonomi, lingkungan alam meliputi tatakelola lingkungan sekolah ditinjau dari aspek kesehatan dan keindahan. 


\section{Daftar Pustaka}

Abdulgani, R.A. (2016). Bimbingan Karir. Bandung: Angkasa.

American School Counselor Association (ASCA). (2008). Elementary School Guidance and Counseling. University of California: American School Counselor Association.

Anderson, G.L., Herr, K., \&Nihlen, A.S. (2007). Studying Your Own School: An Educator Guide to Practitioner Action Research. California: SAGE Publication, Ltd.

Bailey, T. (2010). School-Work: Economic Changes and Educational Reform. Berkeley, C.A.: The National Center for Research in Vocational Education.

Belkin, G.S. (2010). Practical Counseling in the School ( $2^{\text {nd }}$ ed.). Iowa: Wm. C. Brown Company Publishers.

Biklen, S.K.,\& Bogdan. (2007). Qualitative Research for Education. USA: Pearson W.G, Inc.

Blau, et al. (1956). Occupation Choice: A Conceptual Framework,

BPS. (2007). Daerah Istimewa Yogyakarta Dalam Angka 2006. Yogyakarta: BPS Press.

BPS. (2016). Daerah Istimewa Yogyakarta Dalam Angka 2015. Yogyakarta: BPS Press.

Brown, D. (2002). Career Choice and Development (4 ${ }^{\text {th }}$ ed.). San Francisco: Jossey-Bass, Ltd. (2010). Career Information, Career Counseling and Career Development $\left(8^{\text {th }} \mathrm{ed}\right)$. US: Pearson Education, Inc.

Bruce, W., \& Tuckman. (2008). An Age-graded Model for Career Development Education. Journal of Vocational Behavior, 4, 193-212.

BSNP. (2015). Prosedur Operasional Standar Penyelenggaraan Ujian Sekolah Berstandar Nasional Tahun Pelajaran 2015/2016. Jakarta: Dirjendikdasmen.

Burton, D., \&Bartlet, S. (2008) Practitioner Research for Teachers. London: Paul Chapman publishing.

Caldera, et al. (2003). Intrapersonal, Familial, and Cultural Factors in the Commitment to a Career choice of Mexican American and Non-Hispanic White College Women. Journal of Counseling Psychology, 50, 3309-323.

Calhoun, C. C., \& Finch, A. (1976). Vocational Education Concepts and Operations( $2^{\text {nd }}$ ed.). California: Wodsworth Pulishing Company.

Alwasilah,C. (2003). Pokoknya Kualitatif: Dasar-dasar Merancang dan Melakukan Penelitian Kualitatif. Jakarta: PT. Dunia Pustaka.

Chen, M.K., \& Chevalier, J.A. (2008). The Taste for Leisure, Career Choice, and the Returns to Education . Economics Letters: 99, 353-356.

Chudzikowski, K., et al. (2009). Career transitions and their causes: A country-comparative perspective. Journal of Occupational and Organizational Psychology: 82, 825-843.

Crain, W. (2008). Theories of Development: Concepts and Applications $\left(5^{\text {th }}\right.$ ed.) NJ: Prentice Hall

Cresswell, J.W. (2009). Research Design: Qualitative, Quantitative, and Mixed Metdods Approachs. California: SAGE Publication, Inc. 
Crites, J.O., Wallbrown, F.H., \&Blaha, J. (1985). The Career Maturity Inventory: Myths and RealitiesA rejoinder to Westbrook, Cutts, Madison, and Arcia. Journal of Vocational Behavior, 26, 221-238.

Furbish, D., \& Reid, L. (2013). Best practices in career education and development in New Zealand secondary schools. Australian Journal of Career Development, 22(I), 14-20.

Daly, K.J. (2008). Qualitative Methods for Family Studies \& Human Development. California:Sage Publications.

Denzin, N. (2009). The Research Act: A Theoretical Introduction to Sociological Methods. USA: Paperback Printing.

Depdiknas. (2003). Undang-Undang RI Nomor 20 Tahun 2003, tentang Sistem Pendidikan Nasional.

Dewey, J. (2009). Experience and Education. (Terjemahan John de Santo). Illionis: Southern Illionis University Press.

Domenico, M.M., \& Karen, H.J. (2007). Career Aspirations of Women in the $20^{\text {th }}$ Century. Journal of Career and Technical Education, 22. No. 2 Spring.

Elliott, J. (1991). Action Research forEducation Change. Philadelphia: Open Univerity Press.

Emmanuelle,V. (2009). Inter-relationships Among Attachment to Mother and Father, Selfesteem, and Career Indecision. Journal of Vocational Behavior, 75, 91-99.

Farr, M., Satkin, L. (2009). O*NET Dictionary of Occupational Title.m Otis Avenue: JIST.

Farmer,H.S. (1983). Career and Homemaking Plans for High School Youth. Journal of Counseling Psychology, 30, 40-45.

Fassinger, R.E (1985). A Causal Model of College Women's Career Choice. Journal of Vocational Behavior, 27,123-153. . (1990). Causal Models of Career Choice in Two Samples of College Women. Journal of Vocational Behavior, 36,225-248.

Ferreira, J.A., Santos, J.R., Fonseca, A.C., et al. (2007). Early Predictors of Career Development: A 10-year Follow-up Study. Journal of Vocational Behavior, 70, 6177.

Fetterman, D, M. (2010). Ethnography: Step-By-Step $\left(3^{\text {rd }}\right.$ ed). California: SAGE Publication. Inc

Filene, C. (2007). Careers for Women. Boston: Read Books.

Foss, C.J., \&Slaney,R.B. (1986). Increasing Nontraditional Career Choices in Women: Relation of Attitudes Toward Women and Responses to a Career Intervention. Journal of Vocational Behavior, 28, 191-202.

Ganster, D.C., \&Lovell,J.E. (1978). An Evaluation of a Career Development Seminar Using Crites' Career Maturity Inventory. Journal of Vocational Behavior, 13, 172-180.

Gardner, H. (2007). Multiple Intelligences (terj. Alexander Sindoro).

Batam: Interaksara.

Germeijs, V.\&Verschueren, K. (2009). High School Students' Career Decision-Making Process: Consequences for Choice Implementation in Higher Education. Journal of 
Vocational Behavior, 70, 223-241.

Germeijs, V., \&Verschueren, K. (2006). High School Students' Career Decision-Making Process: a Longitudinal Study of One Choice Using Person Matching to Predict Career Specialty Choice. Journal of Vocational Behavior, 68, 189-204.

Gianakos, I. (1999). Patterns of Career Choice and Career Decision-Making Self-Efficacy. Journal of Vocational Behavior, 54, 244- 258.

Gibson, R.L. (2008) Counseling in the Elementary School: a Comprehensive Approach. Michigan: Allyn and Bacon.

Ginzberg, et al. (1951). Occupational Choice: An Approach to a General Theory. NY: Columbia University Presss

Ginsburg, M.B. (1991). Understanding Educational Reform in Global Context: Economiy, Ideology and the State. USA: Taylor \& Francis

Glanz, Edward, C. (1966). Foundations and Principles of Guidance. Boston: Allyn and Bacon, Inc.

Hargrove, B.K., Creagh, M.G., \& Burgess, B.L. (2002). Family Interaction atterns as Predictors of Vocational Identity and Career Decision-making Self-Efficacy. Journal of Vocational Behavior, 61,185-201.

Harmon, L.W. (1981).The Life And Career Plans Of Young Adult College Women: a FollowUp Study. Journal of Counseling Psychology, 28, 416-427.

Harren, V.A., Kass, R.A., Tinsley, H.E., et al.(1979) Influence of Gender, Sex-Role Attitudes, and Cognitive Complexity on Gender-Dominant Career Choices. Journal of Counseling Psychology, 26, 227-234.

Havighurst. (1965). Human Development \& Education. NY: David McKay.co

Hawley, P. (1972). Perceptions of Male Models of Femininity Related to Career Choice. Journal of Counseling Psychology, 19, 308-313.

Hein, G. E. (1991). Constructivist Learning Theory. Paper Present at the CECA Conference, Jerusalem, Israel 15-22 October 1991. Diambil pada tanggal 20 Februari 2004 dari http://www.exploratorium.edu/IFI/ resources/constructivistlearning.html

Hergenhahn, B.R., \&Oslon, M.H. (2009). Theories of Learning (7th). US: Pearson Education

Herr, E.L. (1974). Vocational Guidance and Human Development. Washington, D.C. : Houghton Mifflin Company.

+. (2007).Career Guidance and Counseling Through the Life Span: Systematic Approaches, $\left(6^{\text {th }}\right.$ ed). Michigan: Scott. Foresman/Little, Bown College Division.

Hodges, D., \& Vistarini, B. (2007). Research Degrees by Project. Makalah disampaikan dalam seminar di Universitas Negeri Yogyakarta.

Holland, J.L. (1959). A Theory of Vocational Choice. Journal of Counseling Psychology,6,3545.

. (1973). Making Vocational Choice: A Theory of Career. NJ: Prentice-Hall, Inc.

Hollingsworth, Sandra. (1997). International Action Research: A casebook for Education Reform. Hong Kong: Falmer Press. 
Hopkin, D. (2008).A Teacher Guide to Classroom Research. England: McGraw-Hill Education.

Hoppock, R. (1976). Occupational Information. USA: McGraw-Hill, Inc.

Irene, G. (1995). The Relation of Sex Role Identity to Career Decision-Making Self-Efficacy. Journal of Vocational Behavior, 46, 131-143.

Issaacson, L., \& Duane. (2008). Basics of Career Counseling. USA: Allyn and Bacon, Inc.

James, E.A., \&Bucknam, A. (2008). Participatory Action research for Educational Leadership. California: SAGE Publication, inc.

Jepsen,D.A., Prediger, \&Dale, J. (1981). Dimensions Of Adolescent Career Development: A Multi-Instrument Analysis. Journal of Vocational Behavior, 19, 350-368.

Johnson, B. (2010). Education Research: Quantitative and Qualitative Aproaches. USA: Allyn Bacon.

Kemdikbud. (2015). Rencana Strategis Kementrian Pendidikan dan Kebudayaan 2015-2019. Jakarta: Kemdikbud

Kementrian Ketenagakerjaan RI. (2014). Klasifikasi Baku Jabatan Indonesia (KBJI) 2014. Jakarta: Kementerian Ketenagakerjaan RI.

Kemmis, S., et al.(2002). Action Research in Practice. USA: Routledge

Kemmis, S. (2006). Participatory Action Research and Public Sphere. Educational Action Research, 14. No. 4 2006. 459-476.

Kemmis, S., McTaggart, Robin. (1990). The Action Research Planner. Victoria: Deakin University Press.

Kenton, J.M \& Song, L. (2008). Action Research Practitioner Perspectives. In K. McFerrin et al. (Eds.), Proceedings of Society for Information Technology \& Teacher Education International Conference 2008, 1119-1120. Chesapeake, VA: AACE.

Koshy, V. (2005). Action Research for Improving Practice: A Practical Guide. London: SAGE Publication, Ltd.

Leong, F.T.L., Hardin, E.E., \&Gaylor, M. (2005). Career Specialty Choice: A Combined Rresearch-intervention Project. Journal of Vocational Behavior, 67, 69-86.

Linn, P.L., Ferguson, J., \& Egart, K. (2009). Career Exploration Via Cooperative Education And Lifespan Occupational Choice. Journal of Vocational Behavior, 65, 430-447.

Lorsbach, A., \& Tobin, K. (1992). Constructivism as a Referent for Science Teaching. Inquiry Education Research n.5, 1992.

Ludwikowski W., David, V., \& Armstrong, P.I. (2009). Attitudes Toward Career Counseling: The Role of Public And Self-Stigma. Journal of Counseling Psychology, 56, 408416.

Marland, S.P., Jr. (1971) Marland on career education. American Education 25-28. . (1974). Career Education. NY: McGraw-Hill

McWhirter, E.H., Rasheed, S., \& Crothers, M.(2000). The effects of high school career 
education on social-cognitive variables. Journal of Counseling Psychology, 47(3): 330-341.

McKernan, James. (1996). Curriculum Action Research: A Hanbook of Methods and Resources for The Reflective Practitioner $2^{\text {nd }}$ ed. Oxon: Kogan Page Limited.

McNamara, Olwen. (2002). Becoming an Avidence-Bassed Practitioner: A Frame Work For Teacher-researchers. NY: RoutledgeFalmer.

McNiff, J. (2002). Action Research Principles and Practice. NY: Macmillan Education, Ltd.

McNiff, J., \&Lomax, P. (2003). You and Your Action Research Project (2 $2^{\text {nd }}$ ed.). London: RoutledgeFalmer.

Meriam, S.B. (2009). Qualitative Research A Guide to Design and Implementation. San Francisco: John Wiley and Son.

Mertler, C.A., \& Charles, C.M. (2010). Introduction to Educational Research: International Edition. London: SAGE Publishing Ptd.

Mertler, C.A. (2008). Action research: Teachers as Researchers in the Classroom. London: SAGE Publishing Ptd.

Mikkelsen, B. (2009). Methods for Development Work and Research: A Guide for Practitioners. Sage Publications Inc.

Miles, Matthew B. \& A. Michael Huberman. (2002). Qualitative Data Analysis. London: Sage Publications, Inc.

Millar, R., \&Shevlin, M. (2003). Predicting Career Information-Seeking Behavior of School Pupils Using the Theory of Planned Behavior. Journal of Vocational Behavior, $\underline{62}$, 26- 42.

Miller, C. H. (1961). Foundations of Guidance. New York: Harper and Brothers' Publishers.

Mortensen, Donald, G., \& Schmuller A,M. (1976). Guidance In Today's Schools. (3 ${ }^{\text {rd }}$ ed). USA: John Wiley \& Sons, Inc.

Mulder, N. (2009). Southeast Asia Images: Towards Civil Society? Chiang Mai: Silkworm Books.

Munandir. (1996). Program Bimbingan dan Konseling di Sekolah. Jakarta: Depdikbud.

Murphy, E. (1997). Constructivist Learning Teory. Diambil pada tanggal 21 Oktober 2009 dari http://stemnet.nf.ca/ elmurhy/elmurphy/cle2.html

(1997). Constructivism From Philosophy to Practice. Diambil pada tanggal 21 Oktober 2009 dari http://stemnet.nf.ca/ elmurhy/ elmurphy/cle.html

Murphy, E. (1997). Characteristics of Constuctivist Learning and Teaching. Diambil pada tanggal 21 Oktober 2009 dari http://stemnet.nf.ca/ elmurhy/elmurphy/cle3.html

Myers, G.E. (1941). Principles and Techniques of Vocational Guidance. USA: McGraw-Hill Book Company, Inc.

Nelson, R.R. (1972). Guidance and Counseling in the Elementary School. USA: Holt, Rinehart and Winston, Inc.

Neumark, D., Junfu, Z,.\& Stephen, C.(2008). The Effects of Wal-Mart on Local Labor 
Markets.Journal of Urban Economics, 63, No. 2, 405-430.

Paterson. H. (1967). Vocational Guidance and Career Development. NY: The Macmillan Company.

Reason, P. (2008). Handbook of Action Research: Participative Inquiry andPractice. Singapura: SAGE.

Phillips, S.D., et al. (2007).Career Development of Special Populations: A framework for research. Journal of Vocational Behavior, 22, 12-29.

Pine, G.J. (2009). Teacher Action research: Building Knowledge Democracies. California: SAGE Publication, Inc.

Plotrefera, J.J. (1980). Guidance an Introduction. USA: Rand McNally College Publishing Company.

Popma,J., \&Taylor, K.M. (1990). An Examination of The Relationships Among Career Decision-Making Self-Efficacy, Career Salience, Locus of Control, And Vocational Indecision. Journal of Vocational Behavior, 37,17-31

Prideaux, L.A., Creed, P.A., \& Patton, W. (2007). Predicting Change Over Time in Career Planning and Career Exploration For High School Students. Journal Of Adolescence, 30, 377-392.

Roe, A. (1957). Early Determinants of Vocational Choice. Journal of Counseling Psychology, 4, 212-217.

Sax, L.J., \&Bryant A.N. (2006). The Impact of College on Sex-Atypical Career Choices of Men and Women. Journal of Vocational Behavior, 68, 52-63.

Schloss, J. (2011). Career development in schools: Do teachers have the skills? Australian Journal of Career Development, 2011; 20(3): 4-9.

Schmidt, J.J. (2008). Counseling in School: Comprehensive Programs of Responsive Service For All Students. US: Pearson Education, Inc.

Schmuck, R.A. (ed). (2009) Practical Action Research (2nd ed.). California: SAGE Publication, Inc.

Sherry, P., \& Staley, K. (1984). Career exploration groups: An outcome study. Journal of College Student Personnel 25: 155-159.

Slamet. (2008). Desentralisasi Pendidikan di Indonesia. Handout 2. Kumpulan materi presentasi. Jakarta: Departemen Pendidikan Nasional.

Spradley, James, P. (1997). The Etnographic Interview. London: Sage Pbl.

Sukamto. (2001). Perubahan Karakteristik Dunia Kerja dan Revitalisasi Pembelajaran dalam Kurikulum Pendidikan Kejuruan. Disampaikan dalam pidato pengukuhan Guru Besar dalam Pendidikan Kejuruan Fakultas Teknik Universitas Negeri Yogyakarta.

Sukardi, D.W. (2008). Bimbingan Karir di Sekolah. Jakarta: Ghalia Indonesia.

Suparno, P.(2009). Filsafat Konstruktivisme Dalam Pendidikan. Yogyakarta: Kanisius.

.(2002). Konstruktivisme Dalam Pembelajaran Sains Makalah disampaikan dalam kuliah perdana Program Pascasarjana UNS. Surakarta: uns. 
Super, D.E. (1953). A Theory of Vocational Development. American Psychologist 186-191. (1954). Career Patterns as a Basic for Vocational Counseling. Journal of Counseling Psychology, 1,1, 12-20 . (1957). The Psychology of Career. NY:Harper \& Row Publishers.

Tiedeman, D.V. and O’Hara, R.P. (1963). Career Development: Choice and Adjustment. New York: College Entrance Examination Board.

Taylor, K.M., \& Betz, N.E. (1983). Applications of Self-Efficacy Theory to the Understanding and Treatment of Career Indecision. Journal of Vocational Behavior, 22, 63-81.

Thompson, J.F. (1973). Foundation of Vocational Education. New Jersey: Prentice-Hall, Inc.

Thorndike, E.L. (1925). Biographical Memoir Of Granville Stanley Hall (1846-1924). National Academy Of Sciences Biographical Memoirs Volume Xii Fifth Memoir.Presented To The Academy At The Annual Meeting, 1925.

Uwe, F. (2009). An Introduction to Qualitative Research (4th ed.). India: SAGE Publication Pvt. Ltd.

Van Hoose.(2010). Elementary-School Guidance and Counceling: a Composite View. Virginia: Rand Mc Nally.

Verschueren, K., \& Germeijs, V. (2007). High School Students' Career Decision-Making Process: Consequences for Choice Implementation In Higher Education. Journal of Vocational Behavior, 70, 223-241.

Verschueren, K., Germeijs, V., \& Soenens, B. (2006). Indecisiveness and High School Students' Career Decision-Making Process: Longitudinal Associations and the Mediational Role of Anxiety. Journal of Counseling Psychology, 53, 397-410.

Vorhölter, J. (2009). Towards a Culture of Participation? London: Transaction Publication.

Wahl, K.H., \& Blackhurst, A. (2000). Factors affecting the occupational and educational aspirations of children and adolescents. Professional School Counseling, 3(5): 367374.

Wanda, L.S., \& Tena B.C. (2004). The Delphi Technique: A Research Strategy for Career and Technical Education. Journal Of Career And Technical Education, 20. Number 2.

Wass, G.A. (1984). Cognitive differentiation asa function of information type and its relation to career choice. Journal of Vocational Behavior, 24: 66-72.

Winkel, W.S., \& Srihastuti, M.M. (2009). Bimbingan dan Konseling di Institusi Pendidikan.(Rev. Ed). Yogyakarta: Media Abadi.

Zunker, Vernon, G. (1981). Career Counseling: Applied Concepts of Life Planning. California: Wadsworth, Inc. 